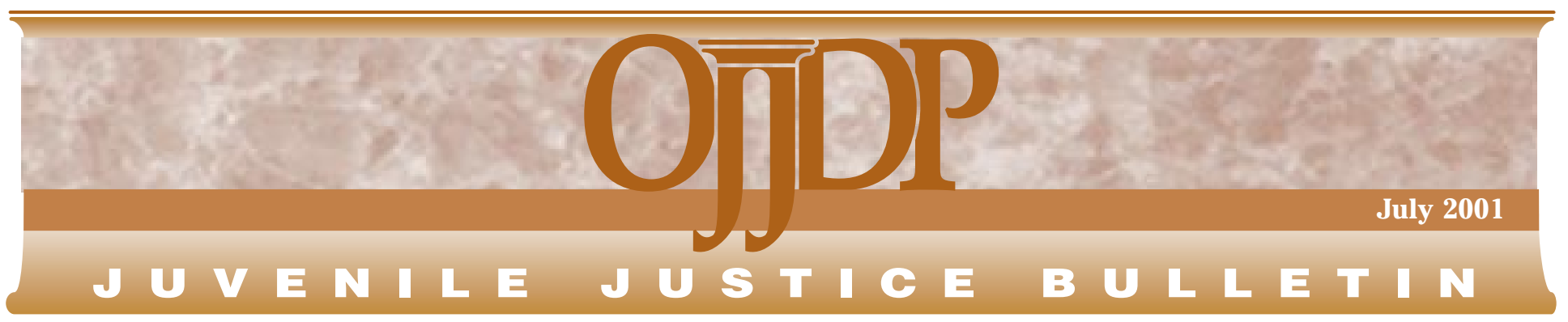

\section{Blueprints for Violence Prevention}

\section{Sharon Mihalic, Katherine Irwin, Delbert Elliott, Abigail Fagan, and Diane Hansen}

Communities often lack the best information on how to assess local needs and how to use an assessment to select a violence reduction/intervention program that fits their needs. Despite strong public pressure to implement programs with proven results, without clear standards and guidelines, communities can become lost in the maze of programs that claim effectiveness in deterring violence yet have no factual information or evidence supporting their effectiveness. The Blueprints for Violence Prevention Initiative is a comprehensive effort to provide communities with a set of programs whose effectiveness has been scientifically demonstrated. With the Office of Juvenile Justice and Delinquency Prevention's (OJJDP's) support, the Initiative also provides the information necessary for communities to begin replicating programs locally.

The Center for the Study and Prevention of Violence (CSPV) at the University of Colorado at Boulder designed and launched the Blueprints for Violence Prevention Initiative in 1996 to identify and replicate effective youth violence prevention programs across the Nation. The Initiative, which was at first funded by the Colorado Division of Criminal Justice, the Centers for Disease Control and Prevention, and the Pennsylvania Commission on Crime and Delinquency, ${ }^{1}$ identified 11 prevention and intervention programs that meet a strict scientific standard of program effectiveness. Program effectiveness is based on an initial review by CSPV and a final review by and recommendations from an advisory board comprising six experts in the field of violence prevention. ${ }^{2}$

The 11 model programs, or Blueprints, have been proven to be effective in reducing adolescent violent crime, aggression, delinquency, and substance abuse and predelinquent childhood aggression and conduct disorders. Another 19 programs have been identified as promising. To date, more than 500 programs have been reviewed, and CSPV continues to look for additional programs that meet the rigorous selection criteria.

This Bulletin describes CSPV's selection criteria in choosing model Blueprints programs, highlights the 11 model programs chosen to date, and discusses replication of Blueprints programs, their funding, and lessons learned from the replication sites.

1 Currently, a majority of the funding support comes from OJJDP.

2 Advisory board members are Tom Cook, Ph.D., Northwestern University; Delbert Elliott, Ph.D., University of Colorado; Denise Gottfredson, Ph.D., University of Maryland; Hope Hill, Ph.D., Howard University; Mark Lipsey, Ph.D., Vanderbilt University; and Patrick Tolan, Ph.D., University of Illinois. Peter Greenwood, Ph.D., The RAND Corporation, is a former board member.

\section{A Message From OJJDP}

As communities seek to prevent and control youth violence, they naturally look to the growing number of effective violence reduction programs that are being implemented across the Nation. How can they accurately assess the relative merits of these competing programs and determine the strategy best suited to meeting their local needs?

Through the Blueprints for Violence Prevention Initiative, OJJDP provides information to communities on a broad array of violence prevention and intervention programs that have been proven to be effective. This Bulletin describes the demanding criteria established by the Center for the Study and Prevention of Violence to designate model Blueprints programs and the activities of the 11 programs out of the more than 500 that have been reviewed to date and found to meet those rigorous standards. Contact information is provided for each program, and replication and funding resources are discussed.

The most significant criterion used in reviewing a program's effectiveness is evidence of its deterrent effect when using a strong research design. The Blueprints programs featured in this Bulletin have demonstrated their effectiveness in reducing adolescent violent crime, aggressive delinquency, substance abuse, and predelinquent aggression and conduct disorders. They merit our attention and consideration. 


\section{Selection Criteria}

The success of a community's violence prevention efforts depends, in large part, on the interventions used. That is why it is imperative to identify approaches that have been proven effective. Although a program model can rarely, if ever, be proved superior to all others, a particular model elicits greater confidence after its theoretical rationale, goals and objectives, and outcome evaluation data have been carefully reviewed. Although various scholarly reviews have identified exemplary programs, the methodological standards used in evaluating program effectiveness can vary greatly. A few of these scholarly reviews actually score each assessed program evaluation on its methodological rigor, but for most, the standards are variable and seldom made explicit. Evaluations of many of the programs did not employ true experimental designs and did not demonstrate statistically significant results. In addition, very few of these recommended programs have been replicated at multiple sites or have demonstrated a sustained deterrent effect after the program ended. In essence, the standard for the claims of program effectiveness in most of these reviews is very low.

In contrast, Blueprints programs meet the most rigorous tests of effectiveness in the field. The most important criterion to be considered when reviewing program effectiveness is evidence of deterrent effect when using a strong research design. Other important criteria are sustained effects and multiple site replication. Blueprints model programs must meet all three of these criteria, while promising programs must meet only the first criterion. Although additional factors are considered in the selection process (see page 3), the three criteria discussed below are given greater weight.

\section{Evidence of Deterrent Effect When Using a Strong Research Design}

As noted above, this is the most important of the selection criteria. Relatively few programs have demonstrated effectiveness in reducing the onset, prevalence, or individual offending rates of violent behavior for juveniles. The Blueprints advisory board accepts evidence of deterrent effects for three key indicators-violence (including childhood aggression and conduct disorder), drug use, and/or delinquencyas evidence of program effectiveness.

\section{Promising Programs Identified by Blueprints for Violence Prevention}

Baltimore Mastery Learning (ML) and Good Behavior Game (GBG)

CASASTART (Striving Together To Achieve Rewarding Tomorrows, from the National Center on Addiction and Substance Abuse)

FAST (Families and Schools Together) Track

I Can Problem Solve

Intensive Protective Supervision Project (IPSP)

LIFT (Linking the Interests of Families and Teachers)

Parent Child Development Center

Perry Preschool Program

Preparing for the Drug-Free Years
Preventive Intervention

Preventive Treatment Program

Project Northland

Project PATHE (Positive Action Through Holistic Education)

Project STATUS (Student Training Through Urban Strategies)

School Transitional Environmental Program (STEP)

Seattle Social Development Project

Strengthening Families Program

Syracuse Family Development Research Program (FDRP)

Yale Child Welfare Project
Providing sufficient quantitative data to document effectiveness requires the use of evaluative designs that afford reasonable confidence in the findings (e.g., experimental designs with random assignment or quasi-experimental designs with matched control groups).

Most researchers recognize random assignment studies (randomized trials) executed faithfully as providing the highest standard of program evaluation. Random assignments offer the most compelling evidence that study results are due to the intervention rather than to preexisting differences between experimental and control groups and other threats to internal validity. ${ }^{3}$ In these studies, assignment to experimental or control conditions is determined solely by chance, and the likelihood of differences being attributed to the assignment process can be assessed.

When random assignment cannot be used, the advisory board considers studies that use control groups matched as closely as possible to experimental groups on relevant characteristics (e.g., gender, race, age, socioeconomic status, income) and studies with control groups that use statistical techniques to control for initial differences on key variables. This is the most

\footnotetext{
${ }^{3}$ An evaluation is valid internally if it is able to eliminate all alternative explanations for a program's results. Threats to internal validity include maturation, selection bias, and testing effects.
}

common method to be used when testing programs in a school environment, for example. As carefully as experimental and control groups are matched, however, it is impossible to determine if the groups will vary on some characteristics that have not been matched or controlled for and that are related to program outcome. Random assignment, therefore, is believed to be the most rigorous of methodological approaches.

Research designs vary greatly in quality, particularly with respect to several key aspects: sample size, attrition (loss of study participants over time), and measurement issues. At a minimum, the following issues need to be addressed:

Sample sizes must be large enough to provide statistical power to detect effects. It is more difficult to detect statistically significant differences between groups when small sample sizes are used.

- Attrition may be indicative of problems in program implementation or may be a failure to locate subjects during a followup period. Attrition is dangerous, particularly because it can compromise the integrity of the original randomization or matching process. It reduces confidence that the original and final samples are comparable and that the final experimental and control comparisons reflect only treatment effects. 
- Tests to measure outcomes must be administered fairly, accurately, and consistently to all study participants. For example, the use of inconsistent measures over time may produce less reliable test scores. The instruments used to measure outcomes should be demonstrated to be reliable and valid.

All Blueprints programs have used strong research designs and demonstrated significant effectiveness in reducing or preventing problem behaviors.

\section{Sustained Effects}

Although one criterion of program effectiveness is that the program demonstrate success by the end of the treatment phase, it is also important to demonstrate that these program effects endure beyond treatment and from one developmental period to the next. Designation as a Blueprints program requires a sustained effect at least 1 year beyond treatment, with no subsequent evidence that this effect is lost. Unfortunately, many programs that demonstrated initial success have failed to show long-term maintenance of the effects after the intervention has ended.

Depending on whether effects are immediate or delayed, the full impact of an intervention or treatment may not be realized at the end of treatment. Significant improvement may be realized over time, or a decay or decline may result. For example, if a program designed to prevent drug use (e.g., Life Skills Training) demonstrates its effectiveness in middle/junior high school when youth first begin encountering peer offers to use drugs, it is also important to demonstrate that these effects are sus-

tained over a longer period of time. Unless this protective effect is sustained through high school, the program is unlikely to have an impact when problem behavior is at its peak. Although programs that have specifically failed to produce a sustained effect do not qualify as Blueprints model programs, those programs that have not yet demonstrated long-term effects may be considered as promising programs.

\section{Multiple Site Replication}

Replication is an important element in establishing program effectiveness and understanding what works best, in which situations, and with whom. Some programs are successful because of unique characteristics in the original site that may be difficult to duplicate in another site (e.g., having a charismatic leader or extensive community support and involvement). Replication establishes the strength of a program and its prevention effects and demonstrates that it can be successfully implemented in other sites.

Programs that have demonstrated success in diverse settings (e.g., urban, suburban, and rural areas) and with diverse populations (e.g., different socioeconomic, racial, and cultural groups) create greater confidence that such programs can be transferred to new settings. As communities prepare to tackle the problems of violence, delinquency, substance abuse, school dropout, and teenage pregnancy, knowledge that a specific program has had success in various settings with similar populations adds to its credibility.

Some projects may initially be implemented as a multisite single design (i.e., several sites are included in the evaluation design). When this occurs, it is preferable to review evaluation results from each site rather than pool the results to assess the project's transportability to other sites. Single site designs with no replication are the least acceptable. Becoming a Blueprints model program requires at least one replication with demonstrated effects.

\section{Additional Factors}

In the selection of Blueprints programs, two additional factors are considered: whether a program conducted an analysis of mediating factors and whether a program is cost effective.

Analysis of mediating factors. The Blueprints advisory board looks for evidence that change in the targeted risk or protective factor(s) mediates the change in violent behavior. This evidence clearly strengthens the claim that program participation is responsible for changes in violent behavior, and it contributes to the theoretical understanding of the causal processes involved. In its reviews of different programs, the advisory board has discovered that many programs reporting significant deterrent "main effects" have not collected the data necessary to complete an analysis of mediating factors.

Costs versus benefits. Program costs should be reasonable and should be less or no greater than the program's expected benefits. High-price-tag programs are difficult to sustain when competition is high and funding resources are low. Implementing expensive programs that will, at best, have small effects on violence is counterproductive. Although outcome evaluation research established that Blueprints programs were effective in reducing violence, delinquency, and drug use, very few data were available initially regarding the costs associated with replicating these violence prevention programs. A meta-analysis of mean effect sizes $^{4}$ of "best" programs had shown that such programs (e.g., behavioral programs, interpersonal skills training, multiple services programs) could reduce recidivism rates between 20 and 40 percent (Lipsey, 1992, 1999). ${ }^{5}$ What was unclear was whether the benefits of providing these programs outweighed the costs. Two recent cost-benefit studies involving Blueprints programs-the RAND Corporation study (Greenwood et al., 1996) and a study of the Washington State Institute for Public Policy (Aos et al., 1999)suggest that they are cost effective.

The RAND Corporation study (Greenwood et al., 1996) compared four different crime prevention approaches with California's “Three Strikes and You're Out" law (Cal. Penal Code $§ 667,1994)$, which guarantees extended sentences for repeat offenders, to determine the benefits of programs that divert at-risk youth from crime. The four approaches were high school graduation incentives (e.g., Quantum Opportunities Program), parent training (e.g., Functional Family Therapy), delinquent supervision (e.g., programs using intensive supervision), and home visitation/daycare (e.g., Prenatal and Infancy Home Visitation by Nurses, Perry Preschool Program).

Three of these approaches (graduation incentives, parent training, and delinquent supervision) compared favorably with the Three Strikes law in terms of serious crime prevented per dollar expended; the first two were dramatically more cost effective. Graduation incentives were the most cost effective, preventing 250 serious crimes per $\$ 1$ million program dollars (a cost of $\$ 4,000$ per serious crime prevented). Parent training interventions were the next most cost effective, preventing 160 crimes per $\$ 1$ million spent ( $\$ 6,500$ per serious crime prevented).

\footnotetext{
${ }^{4}$ Effect size is the change in outcome as a result of an intervention.

5 The classification of "best" programs was determined by this meta-analysis, which is defined as "the statistical analysis of a large collection of analysis results from individual studies for the purpose of integrating the findings" (Glass, 1976:3).
} 
These two approaches were much more cost effective than the Three Strikes law, which prevented 62 crimes per $\$ 1$ million spent $(\$ 16,000$ per serious crime prevented). Although the comparison was less dramatic for the delinquent supervision interventions, which prevented about 70 crimes per $\$ 1$ million spent ( $\$ 14,000$ per serious crime prevented), these interventions also were more cost effective than the Three Strikes law.

Only the home visitation/daycare intervention was less cost effective than the Three Strikes law, preventing 11 crimes per $\$ 1$ million spent $(\$ 90,000$ per serious crime prevented). Because home visitation/daycare occurs during the first 5 years of childhood, up to 15 years pass before the intervention can begin to affect serious street crimes, which typically occur as youth enter puberty. Child abuse, however, is affected immediately and is typically not included in cost-benefit analyses focusing solely on criminal justice cost savings. Other substantial favorable results found in areas such as child health and development, educational achievement, and economic well-being, which generate government savings that exceed program costs, are not included in these analyses.

The Washington State Institute for Public Policy (Aos et al., 1999) completed a costbenefit study of programs dealing with age groups from early childhood through adulthood. The Institute examined the costs of crime to taxpayers (i.e., criminal justice costs) and to victims who suffer personal and property losses. Several programs had benefits that exceeded costs. The table below presents the costs versus the benefits of Blueprints programs examined in this study.

Programs designed for juvenile offenders had the largest and most consistent economic returns (e.g., Functional Family Therapy, Multisystemic Therapy, Multidimensional Treatment Foster Care). Programs that target younger juveniles who are not already involved in the criminal justice system have smaller returns when considering savings in criminal justice costs. Their benefits, however, can be calculated in other ways, such as savings to the health and welfare system. Many of these programs, such as the Prenatal and Infancy Home Visitation by Nurses and Quantum Opportunities programs, have reduced the amount of Temporary Assistance to Needy Families (formerly called Aid to Families with Dependent Children), the number of babies born with low birth weight, the incidence of school dropout, and the unemployment rate.

\section{Model Program Descriptions}

The selection criteria identified above establish a high standard, one that has proved difficult for most programs to meet, thus explaining why there are only 11 Blueprints programs. This high standard reflects the level of confidence necessary, however, for recommending that communities replicate these programs with reasonable assurances that they will prevent violence. The programs, which are described below in a developmental sequence, have been identified as Blueprints because they have met this standard and have been proven effective in reducing adolescent violent crime, aggression, delinquency, and/or substance abuse. As time goes on and new research findings are published, CSPV hopes to add other credible, effective programs that communities can use confidently.

\section{Prenatal and Infancy Home Visitation by Nurses}

The most serious and chronic offenders often show signs of antisocial behavior as early as the preschool years (American Psychiatric Association, 1994). Three risk factors associated with early development of antisocial behavior can be modified: adverse maternal health-related behaviors during pregnancy, child abuse and neglect, and troubled maternal life course.

Prenatal and Infancy Home Visitation by Nurses sends nurses to the homes of lowincome, first-time mothers to improve their health, parenting skills, and chances of giving birth to children free of health and developmental problems. Nurses begin visiting first-time mothers during pregnancy and continue the visits until the child is 2 years old. During home visits, nurses promote the physical, cognitive, and social-emotional development of the children and provide general support and instruction in parenting skills to the parents. The following components are fundamental to the program's effectiveness:

\section{Cost-Benefit Analysis of Selected Blueprints Programs}

\begin{tabular}{|c|c|c|c|c|c|}
\hline \multirow[b]{2}{*}{ Blueprints Program } & \multirow[b]{2}{*}{$\begin{array}{c}\text { Cost per } \\
\text { Participant }\end{array}$} & \multicolumn{2}{|c|}{ Taxpayer Cost Savings } & \multicolumn{2}{|c|}{$\begin{array}{l}\text { Taxpayer and Crime } \\
\text { Victim Cost Savings }\end{array}$} \\
\hline & & $\begin{array}{c}\text { Per } \\
\text { Participant }^{*}\end{array}$ & $\begin{array}{c}\text { Benefits per } \\
\text { Dollar of Cost }{ }^{\dagger}\end{array}$ & $\begin{array}{c}\text { Per } \\
\text { Participant }^{*}\end{array}$ & $\begin{array}{c}\text { Benefits per } \\
\text { Dollar of Cost }\end{array}$ \\
\hline \multicolumn{6}{|l|}{ Multidimensional } \\
\hline Treatment Foster Care & $\$ 1,934.00$ & $\$ 27,202.00$ & $\$ 14.07$ & $\$ 43,661.00$ & $\$ 22.58$ \\
\hline Multisystemic Therapy & $4,540.00$ & $38,047.00$ & 8.38 & $61,068.00$ & 13.45 \\
\hline Functional Family Therapy & $2,068.00$ & $14,167.00$ & 6.85 & $22,739.00$ & 11.00 \\
\hline Big Brothers Big Sisters & $1,009.00$ & $1,313.00$ & 1.30 & $2,143.00$ & 2.12 \\
\hline Nurse Home Visitation & $7,403.00$ & $6,155.00$ & 0.83 & $11,369.00$ & 1.54 \\
\hline Quantum Opportunities & $18,292.00$ & $1,582.00$ & 0.09 & $2,290.00$ & 0.13 \\
\hline
\end{tabular}

* Estimated total dollar amount of benefits expected to be received in avoided criminal justice costs.

$\uparrow$ Taxpayer cost savings per participant divided by the cost per participant. Values greater than $\$ 1.00$ indicate that the program's crime-reducing benefits are greater than its costs.

* Taxpayer and crime victim cost savings per participant divided by the cost per participant.

Source: Adapted from Aos et al., 1999. 


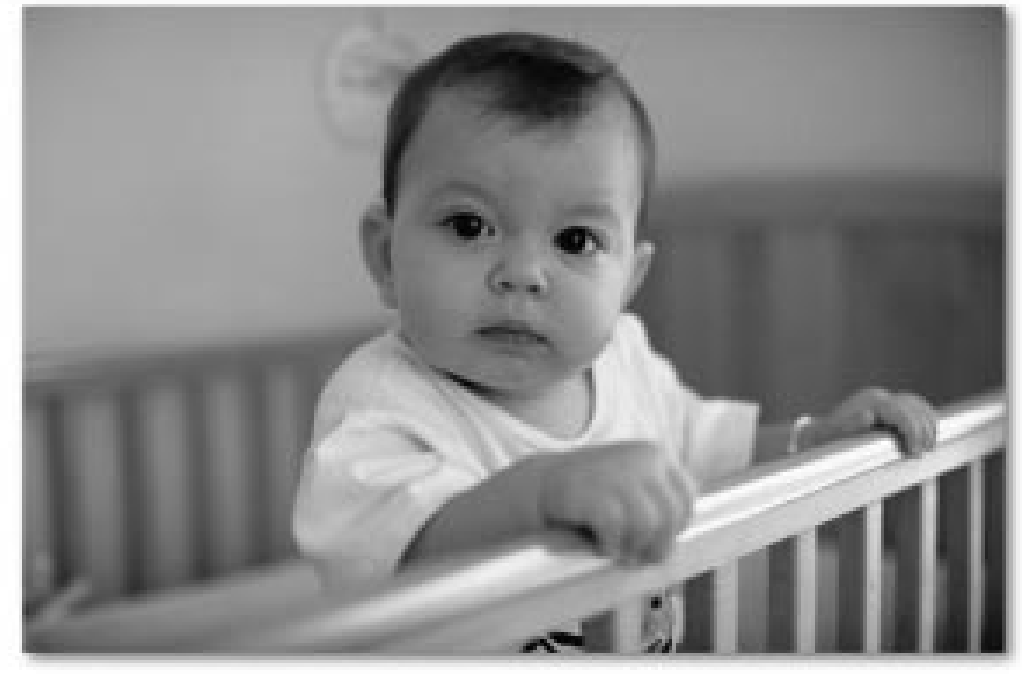

- Trained and experienced nurses who have strong interpersonal skills and a maximum caseload of 25 families make the home visits.

- Families are visited every 1 to 2 weeks.

- Nurses focus simultaneously on the mother's personal health and development, environmental health, and quality of caregiving.

Visiting nurses help young parents gain the confidence and skills necessary to set and achieve goals such as completing their education, finding work, and avoiding unplanned pregnancies (Olds et al., 1997).

Nurse home visitation has had positive outcomes on obstetrical health, psychosocial functioning, and other healthrelated behaviors. One study found that women who smoked 10 or more cigarettes per day during pregnancy when they entered the nurse home visitation program reduced their smoking by approximately 3 cigarettes per day and improved their diets. On followup, the children of these women showed no intellectual impairments, whereas the children of mothers who smoked 10 or more cigarettes per day during pregnancy and did not receive nurse home visits did have impaired intellectual functioning (Olds, Henderson, and Tatelbaum, 1994a, 1994b).

The program also has helped reduce rates of child abuse and neglect by helping young parents learn effective parenting skills and deal with a range of issues such as depression, anger, impulsiveness, and substance abuse. One study found that participation in the program was associated with a 79-percent reduction in State-verified cases of child abuse and neglect among mothers who were poor and unmarried (Olds et al., 1997). In their second year of life, nurse-visited children had 56 percent fewer visits to emergency rooms for injuries and ingestions than children who were not visited (Olds et al., 1986).

During the first 15 years after delivery of their first child, low-income, unmarried women who received nurse home visits had 31 percent fewer subsequent births, longer intervals between births (an average of 2 years), fewer months on welfare (60 versus 90 months), 44 percent fewer behavioral problems, 69 percent fewer arrests, and 81 percent fewer criminal convictions than those in the control group.

Adolescents whose mothers received nurse home visits more than a decade earlier were 60 percent less likely to have run away, 55 percent less likely to have been arrested, and 80 percent less likely to have been convicted of a crime than adolescents whose mothers did not receive visits (Olds et al., 1998). They also smoked fewer cigarettes per day, had consumed less alcohol in the past 6 months, and exhibited fewer behavioral problems related to alcohol and drug use.

When the program focuses on low-income women, program costs are recovered by the time the first child reaches age 4 (Olds et al., 1993). The RAND Corporation estimated that once the child reaches age 15, cost savings are four times the original investment because of reductions in crime, welfare expenditures, and healthcare costs and as a result of taxes paid by working parents (Karoly et al., 1998).

\section{Contact Information}

Matthew Buhr-Vogl, Site Development Specialist

National Center for Children, Families, and Communities

1825 Marion Street

Denver, CO 80218

303-864-5839

303-864-5236 (fax)

buhr-vogl.matthew@tchden.org

\section{The Incredible Years Series}

Aggression in young children is escalating-and at younger ages (Campbell, 1990). Young aggressive children may have already established a pattern of social difficulty in preschool that continues and becomes fairly stable by middle school. Many children with conduct problems (defined as high rates of aggression, defiance, and oppositional and impulsive behaviors) have been asked to leave four or five schools by age 6 , and by the time they enter middle school, their negative reputation and their rejection by peers and parents may be well-established (Coie, 1990). Early intervention is key in reducing aggressive behavior and a negative reputation before they develop into permanent patterns.

The Incredible Years Parent, Teacher, and Child Training Series is a comprehensive set of curriculums-parent training, teacher training, and child trainingdesigned to promote social competence and prevent, reduce, and treat conduct problems in young children. Program targets are children ages 2 to 8 who exhibit or are at risk for conduct problems. Trained facilitators use interactive presentations, videotape modeling, and roleplaying techniques to encourage group discussion, problem solving, and sharing of ideas.

The parent training component comprises three series: BASIC, ADVANCE, and SCHOOL. BASIC is the core element of program delivery; the other two series in the parent training component-and the teacher and child training components discussed below-are recommended elements of program delivery. BASIC teaches parents interactive play and reinforcement skills, nonviolent discipline techniques, logical and natural consequences, and problem-solving strategies. ADVANCE addresses family risk factors such as depression, marital discord, poor coping skills, poor anger management, and lack 


\section{Blueprints for Violence Prevention}

The programs chosen to be part of the Blueprints for Violence Prevention Initiative have been described in a series of documents published by the Center for the Study and Prevention of Violence (CSPV). The 11 volumes are designed to be practical documents to be used by communities, agencies, and interested sites in choosing whether any of the Blueprints programs are appropriate for their situation, needs, and available resources.

The Blueprints volumes listed below are available for $\$ 15$ from CSPV (see page 14 for contact information). Information about each of the Blueprints programs is accessible on CSPV's Web site at www.colorado.edu/cspv/blueprints, where a downloadable copy of chapter 1 of each publication is available.

Book One: The Midwestern

Prevention Project, 1998.

Book Two: Big Brothers Big Sisters of America, 1997.

Book Three: Functional Family Therapy, 2000.

Book Four: The Quantum Opportunities Program, 1998.

Book Five: Life Skills Training, 1998.

Book Six: Multisystemic Therapy, 1998.
Book Seven: Prenatal and Infancy Home Visitation by Nurses, 1998.

Book Eight: Multidimensional Treatment Foster Care, 1998.

Book Nine: Bullying Prevention

Program, 2000.

Book Ten: Promoting Alternative THinking Strategies, 1998.

Book Eleven: The Incredible Years Series, 2001. of support. SCHOOL focuses on ways to further youth's academic and social competence.

The teacher training component focuses on strengthening teachers' classroom management skills. It seeks to help teachers encourage and motivate students, promote students' prosocial behavior and cooperation with peers and teachers, teach anger management and problemsolving skills, and reduce classroom aggression.

The child training component, known as the Dina Dinosaur curriculum, emphasizes skills related to developing emotional literacy, having empathy with others or taking their perspective, making and keeping friends, managing anger, solving interpersonal problems, following school rules, and succeeding at school. It is designed for use as a "pull out" treatment program for small groups of children who exhibit conduct problems.

In six randomized trials, the parent training component of The Incredible Years Series has been shown to reduce conduct problems and improve parenting interactions; these improvements have been sustained up to 3 years after the intervention (Webster-Stratton, 1990). The cycle of aggression appears to have been halted for approximately two-thirds of families whose children have conduct disorders and who have been treated in clinics. In two randomized trials, the teacher training component has been shown to improve children's behavior in the classroom (improvements include less hyperactivity, antisocial behavior, and aggression and more social and academic competence) and teachers' classroom management skills (Webster-Stratton, Reid, and Hammond, 2000). The child training component resulted in significantly improved social skills and positive conflict management strategies with peers, in addition to reduced child behavior problems at home and school (Webster-Stratton and Hammond, 1997).

Several hundred service agencies in the United States, Canada, the United Kingdom, Norway, and Australia have adopted at least one of the three series in the Incredible Years parent training component. Funding to purchase the programs may be obtained from local PTA (Parent Teacher Association) groups or from charitable organizations. Once the initial costs of the materials and group leader training have been assumed, these programs can be offered at minimal cost.

\section{Contact Information}

Carolyn Webster-Stratton 1411 Eighth Avenue West Seattle, WA 98119

206-285-7565 (phone and fax)

888-506-3562 (toll-free phone and fax) incredibleyears@seanet.com www.incredibleyears.com

\section{Promoting Alternative THinking Strategies}

The need for universal, school-based curriculums promoting social and emotional competence and decreasing risk factors associated with maladjustment prompted the creation of Promoting Alternative THinking Strategies (PATHS). The program, a school-based intervention, is taught by teachers of students in kindergarten through fifth grade as part of the regular curriculum. PATHS, which is designed to be taught 3 times per week for at least 20 minutes per session, includes lessons in self-control, emotional understanding, selfesteem, relationships, and interpersonal problem-solving skills. Focusing on these protective factors provides youth with tools that enable them to achieve better academically in elementary school. In addition, PATHS helps enhance classroom atmosphere and the learning process.

Lessons are sequenced according to increasing developmental difficulty and include activities such as dialoguing, role-playing, storytelling, modeling by teachers and peers, and social and selfreinforcement. Among other lessons, youth are taught to identify and label their feelings; express, understand, and regulate their emotions; understand the difference between feelings and behaviors; control impulses; and read and interpret social cues. Youth are given activities and strategies to use inside and outside the classroom, and parents receive program materials to reinforce behaviors at home.

Studies have compared classrooms receiving the intervention with matched controls using populations of normally adjusted students, behaviorally at-risk students, and deaf students. Compared with the control groups, youth in the PATHS program have done significantly better in recognizing and understanding emotions, understanding social problems, developing effective alternative solutions, and decreasing frequency of aggressive/ violent solutions. Teachers reported significant improvements in children's self-control, emotional understanding, 
ability to tolerate frustration, and use of conflict resolution strategies. Among special needs youth, teachers reported decreases in internalized symptoms (sadness, anxiety, and withdrawal) and externalized symptoms (aggressive and disruptive behavior).

\section{Contact Information}

Mark T. Greenburg, Ph.D.

Prevention Research Center for the

Promotion of Human Development Pennsylvania State University 110 Henderson Building South

University Park, PA 16802-6504

814-863-0112

814-865-2530 (fax)

prevention@psu.edu

www.prevention.psu.edu

\section{Bullying Prevention Program}

The Bullying Prevention Program was developed, refined, and systematically evaluated in Bergen, Norway, after three young Norwegian boys committed suicide as a consequence of severe bullying by peers. The original project, which took place from 1983 to 1985, involved 2,500 youth in 42 schools throughout the city. According to more than 150,000 Norwegian and Swedish students ages 7-16 who completed a bully/victim questionnaire, 15 percent had been involved in bully/ victim problems. Of these, 5 percent had been frequent targets of bullies or had bullied frequently (once a week or more). In a recent U.S. study, 23 percent of more than 6,000 middle school students in rural South Carolina reported that they had been bullied several times or more during the past 3 months; 20 percent claimed they had bullied others with the same frequency (Melton et al., 1998). Because bullying is such a prevalent problem, the Program has been replicated throughout Norway and in other countries, including the United States.

Bullying causes its victims humiliation, unhappiness, and confusion. Many tend to lose their self-esteem and become anxious and insecure; often their concentration and learning suffer and they may fear and refuse to go to school. Many who suffer persistent bullying as youth feel the impact of that experience into adulthood (Olweus, 1993b). Moreover, bullies often begin acting out in other ways, such as vandalizing property, shoplifting, skipping school, and using drugs. School bullies also are at increased risk for committing crime in adulthood: 60 percent of males who were bullies in grades 6-9 were convicted of at least one crime as adults, compared with 23 percent of males who did not bully; and 35 to 40 percent of these former bullies had three or more convictions by age 24 , compared with 10 percent of those who did not bully (Olweus, 1993a).

The Program's major goal is to reduce bullying among elementary, middle, and junior high school children by reducing opportunities and rewards for bullying behavior. School staff are largely responsible for introducing and carrying out the Program, and their efforts are directed toward improving peer relations and mak-

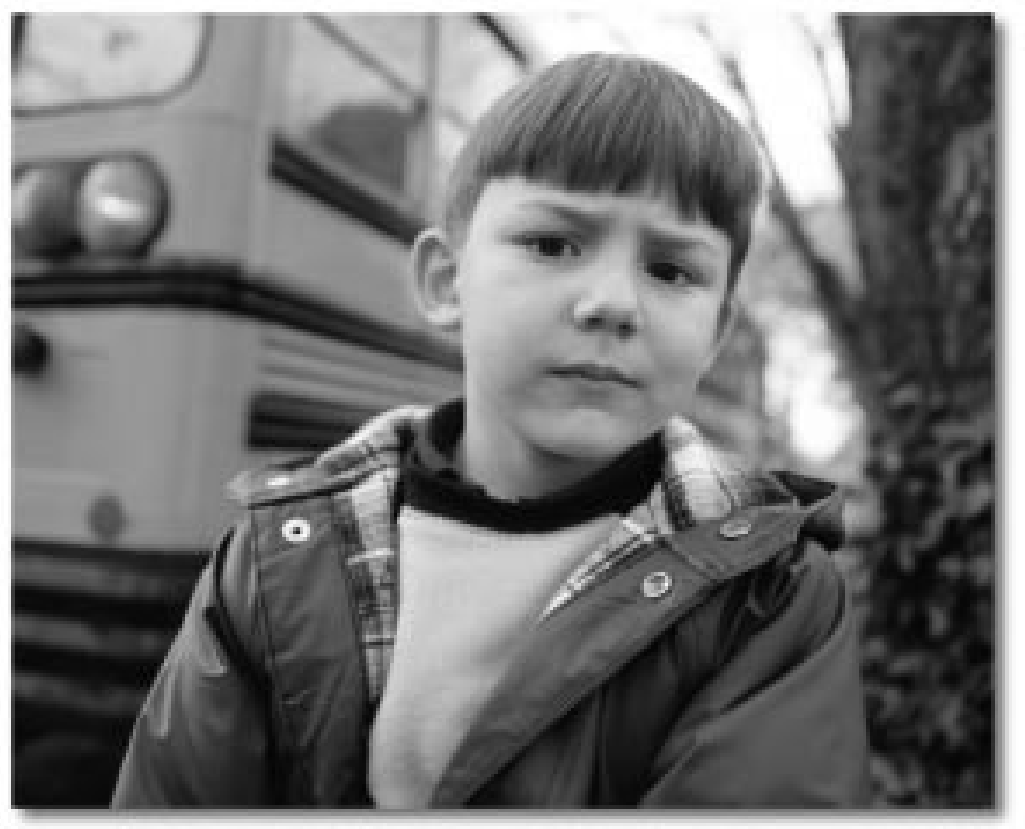

ing the school a safe and pleasant environment. Bullying Prevention increases awareness of and knowledge about the problem, actively involves teachers and parents, develops clear rules against bullying behavior, and provides support and protection for bullying victims. Core components of the Program are at three levels:

School. School personnel disseminate an anonymous student questionnaire to assess the nature and prevalence of bullying, discuss the problem, plan for program implementation, form a school committee to coordinate program delivery, and develop a system of supervising students during breaks.

- Classroom. Teachers and/or other school personnel introduce and enforce classroom rules against bullying, hold regular classroom meetings with students, and meet with parents to encourage their participation.

- Individual. Staff hold interventions with bullies, victims, and their parents to ensure that the bullying stops.

The use of school, classroom, and individual interventions ensures that students are exposed to a consistent, strong message from different people in different contexts regarding the school's views of and attitudes toward bullying.

In Bergen, Norway, the frequency of bullying problems decreased by 50 percent or more in the 2 years following the original project. These results applied to both boys and girls and to students across all grades studied. In addition, school climate improved and the rate of antisocial behavior in general such as theft, vandalism, and truancy dropped during the 2year period. In the South Carolina replication site, the Program slowed the rate of increase in youth's engagement in antisocial behavior. In addition, students reported that they bullied other students less after 7 months in the Program (a 25percent reduction in the rate of bullying).

\section{Contact Information}

Dan Olweus, Ph.D.

University of Bergen

Research Center for Health Promotion

Christies gt. 13, N-5015

Bergen, Norway

47-55-58-23-27

47-55-58-84-22 (fax)

olweus@psych.uib.no 
Susan Limber, Ph.D.

Institute on Family and Neighborhood Life Clemson University

158 Poole Agricultural Center

Clemson, SC 29634

864-656-6320

864-656-6281 (fax)

slimber@clemson.edu

\section{Big Brothers Big Sisters of America}

Big Brothers Big Sisters of America (BBBSA) began in the early 20th century as a means to reach youth who were in need of socialization, firm guidance, and connection with positive adult role models. BBBSA, with a network of more than 500 local programs throughout the Nation, continues to operate as the largest and best known mentoring organization in the United States, maintaining more than 100,000 one-to-one relationships between youth and volunteer adults.

Volunteer mentors are screened and trained, and matches are made carefully using established procedures and criteria. Individual BBBSA agencies adhere to national guidelines but customize their programs to fit local circumstances. The program serves youth ages 6 to 18 , a significant number of whom are from disadvantaged single-parent households. A mentor meets with his or her youth partner at least three times a month for 3 to 5 hours, participating in activities that enhance communication skills, develop relationship skills, and support positive decisionmaking. Such activities are determined by the interests of the child and the volunteer and could include taking walks, attending school activities or sporting events, playing catch, visiting the library, or just sharing thoughts and ideas about life.

Sites may run into two obstacles when setting up a mentoring program in their communities: the limited number of adults available to serve as mentors and the scarcity of organizational resources necessary to carry out a successful program. Although BBBSA maintains more than 100,000 matches between volunteers and youth, estimates reveal that between 5 and 15 million children could benefit from a mentoring program (Grossman and Garry, 1997). An 18-month study of eight BBBSA affiliates found that when compared with a control group on a waiting list for a match, youth in the mentoring program were 46 percent less likely to start using drugs, 27 percent less likely to

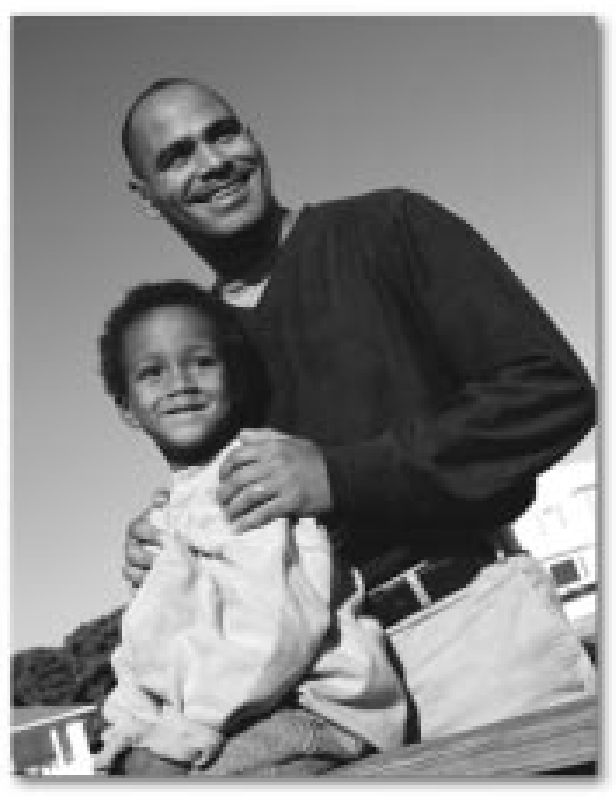

or seventh grade. The 3-year curriculum includes 15 sessions taught in the first year of the program by regular classroom teachers with booster sessions provided in years 2 and 3 . The three basic components of the program teach youth (1) personal self-management skills (e.g., decisionmaking and problem solving, selfcontrol skills for coping with anxiety, and self-improvement skills), (2) social skills (e.g. communication and general social skills), and (3) information and skills designed to have an impact on youth's knowledge and attitudes concerning drug use, normative expectations, and skills for resisting drug use influences from the media and peers.

LST has been found to cut alcohol, tobacco, and marijuana use among young adolescents by 50 to 75 percent. Longterm results of the program reveal a 66percent reduction in polydrug use (use of tobacco, alcohol, and marijuana), a 25percent reduction in pack-a-day smoking, and a decrease in the use of inhalants, narcotics, and hallucinogens. Long-term followup data reveal that reductions can last through 12 th grade.

\section{Contact Information}

Gilbert Botvin, Ph.D., President

National Health Promotion Associates, Inc. 141 South Central Avenue, Suite 208

Hartsdale, NY 10530

914-421-2525

914-683-6998 (fax)

www.lifeskillstraining.com

\section{Life Skills Training}

The most common approaches to substance abuse prevention for the past two decades have involved either the presentation of information concerning the dangers of drug use or the use of classroom discussion and classroom activities designed to enrich youth's personal and social development. These approaches do not address the risk factors for substance abuse among youth and therefore are largely ineffective. Life Skills Training (LST), however, is based on an understanding of the causes of tobacco, alcohol, and drug use and has been designed to target the psychosocial factors associated with the onset of drug involvement.

LST, a drug prevention program focusing on tobacco, alcohol, and marijuana, targets the psychosocial factors associated with the onset of drug involvement by providing drug-related resistance skills training and general life skills training to middle school students beginning in sixth

\section{Midwestern Prevention Project}

Many researchers, policymakers, and drug prevention program planners have begun to question whether single-channel programs (i.e., those implemented entirely within one setting) are effective in promoting significant and lasting changes in youth's drug use behavior. To ensure that its drug prevention message is heard throughout the community in many settings, the Midwestern Prevention Project (MPP), also known as Project STAR, integrates a school-based program with parent, community, mass media, and local policy components.

MPP's goals are to decrease the rates of onset and prevalence of gateway (tobacco, alcohol, and marijuana) and other drug use in youth ages 10-15 and, secondarily, to decrease drug use among parents and other community residents. To achieve these goals, MPP targets the person-, situation-, and environment-level 
factors believed to be responsible for higher levels of drug use, including prior use, low level of resistance skills, perceived norms for use, peer pressure to use, lack of social support for nonuse, and school and community norms.

The program consists of five components: school program, parent education campaign, mass media, community organization and training, and local policy change. The school program teaches active social learning techniques (e.g., modeling, roleplaying, discussion) and assigns homework designed to involve family members. The parent education campaign involves parent-child communication training and a parent-principal committee that meets to review the school drug policy. The other three components deliver a consistent message to the community supporting drug-free living. Collectively, the components focus on promoting youth's drug use resistance and counteraction skills (direct skills training), parents' and other adults' prevention practices and support of adolescent prevention practices (indirect skills training), and the community's dissemination and support of social norms and expectations against drug use (environmental support).

MPP has been shown to reduce marijuana use and daily cigarette smoking by approximately 40 percent among program participants, with smaller reductions in alcohol use. These reductions were maintained through age 12 . Reductions in daily smoking, heavy use of marijuana, and use of some hard drugs have been shown through early adulthood (age 23). MPP also has helped decrease parental alcohol and marijuana use and increase positive parent-child discussion about drug use prevention.

\section{Contact Information}

Mary Ann Pentz, Ph.D.

U.S.C. Norris Comprehensive Cancer Center University of Southern California

1441 Eastlake Avenue, MC9175

Los Angeles, CA 90089-9175

323-865-0327

323-865-0134 (fax)

pentz@hsc.usc.edu

\section{Functional Family Therapy}

Many communities turn to punitive measures to deal with juvenile crime. Mounting evidence suggests, however, that removing youth from their homes and families is costly and ineffective. Punitive programs that separate youth and their families can be detrimental to a youth's long-term progress. Youth's behavioral problems are deeply embedded in their psychosocial systems (e.g., family and community); to be effective, therefore, interventions should treat youth while addressing their complex multidimensional problems.

Functional Family Therapy (FFT) is a short-term, well-documented program that has been applied successfully to a wide range of problem youth and their families in various contexts (e.g., rural, urban, multicultural, international) and treatment systems (e.g., clinics, homebased programs, juvenile courts, independent providers). Researchers designed this multisystemic program to help diverse populations of underserved and at-risk youth and their families who often enter the system angry, hopeless, and/or resistant to treatment.

On average, participating youth attend 12 1-hour sessions spread over 3 months; more difficult cases require 26 to 30 hours of direct service. FFT clearly identifies three treatment phases, each of which includes descriptions of goals, requisite therapist characteristics, and techniques:

- Phase 1: Engagement and motivation. Phase 1 applies reattribution and related techniques to address maladaptive perceptions, beliefs, and emotions. ${ }^{6}$ Use of such techniques serves to help targeted youth and their families increase hope and their expectations of change, respect for individual differences and values, and trust between family and therapist; reduce resistance; and overcome the intense negativity within the family and between the family and community that can prevent change.

- Phase 2: Behavior change. FFT clinicians develop and implement intermediate and long-term behavior change plans that are culturally appropriate, context sensitive, and tailored to the unique characteristics of each family member.

- Phase 3: Generalization. FFT clinicians help families apply positive family change to other problem areas and/or situations, maintain changes, and prevent relapse. To ensure longterm support of changes, FFT links families with available community resources.

${ }^{6}$ Reattribution, or reframing, assigns negative consequences to situational causes rather than to individual pathologies.
Success has been demonstrated and replicated for more than 25 years with a wide range of interventionists, including paraprofessionals and trainees representing the various professional degrees. Controlled comparison studies with followup periods of 1,3 , and 5 years have demonstrated significant and long-term reductions in youth reoffending and in sibling entry into highrisk behaviors. Comparative cost figures demonstrate very large reductions in daily program costs compared with other treatment programs.

In the Nation's largest FFT research and practice site, 80 percent of the families receiving FFT services completed the treatment, a high completion rate compared with the rate for standard interventions. Of those who completed the program, 19.8 percent committed an offense in the year following completion, compared with 36 percent of youth in the control group.

On average, FFT treatment in this practice site cost between $\$ 700$ and $\$ 1,000$ per family for a 2-year study period. By contrast, the average cost of detention was at least $\$ 6,000$ per youth, and the average cost of a county residential program was at least $\$ 13,500$ per youth for the same time period.

\section{Contact Information}

James F. Alexander, Ph.D.

Department of Psychology

University of Utah

390 South 1530 East, Room 502

Salt Lake City, UT 84112

801-585-1807

jfafft@psych.utah.edu

www.fftinc.com

\section{Multisystemic Therapy}

Multisystemic Therapy (MST) was developed to provide scientifically validated, cost-effective, community-based treatment to youth with serious behavior disorders who are at high risk of out-of-home placement. Before MST, such treatment was generally unavailable, and youth often were placed out-of-home in expensive treatment or psychiatric facilities or were incarcerated. MST views individuals as living within a complex social network encompassing individual, family, and extrafamilial (peer, school, neighborhood) factors. Behavioral problems can stem from problematic interactions within the social network, and MST specifically targets the multiple factors that can contribute to antisocial behavior. MST uses the strengths in each youth's social network to promote positive change in his or 
her behavior. The overriding purpose of MST is to help parents deal effectively with their youth's behavioral problems; help youth cope with family, peer, school, and neighborhood problems; and reduce or eliminate the need for out-of-home placements. To empower families, MST also addresses identified barriers to effective parenting (e.g., parental drug abuse, parental mental health problems) and helps family members build an indigenous social support network involving friends, extended family, neighborhoods, and church members.

To increase family collaboration and enhance generalization, MST is typically provided in home, school, and community locations. Treatment is designed with input from the family being served, and this approach encourages collaboration and participation. Therapists with low caseloads-who are available 24 hours per day, 7 days per week-provide the treatment, placing developmentally appropriate demands for responsible behavior on youth and their families. Intervention plans include strategic family therapy, structural family therapy, behavioral parent training, and cognitive behavior therapies.

To address the known causes of delinquency, MST focuses on the individual youth and his or her family, peer context, school/vocational performance, and neighborhood/community supports. Family interventions seek to promote the parents' capacity to monitor and discipline their children, peer interventions remove offenders from deviant peer groups and help them develop relationships with prosocial peers, and school/vocational interventions enhance the youth's capacity for future employment and financial success. The average duration of treatment is approximately 4 months, which includes approximately 60 hours of face-to-face therapist-family contact.

Program evaluations have revealed 25- to 70-percent reductions in long-term rates of rearrest and 47- to 64-percent reductions in out-of-home placements. Moreover, families receiving MST reported extensive improvements in family functioning and decreases in youth's mental health problems. Positive results were maintained after almost 4 years.

Despite its intensity, MST has been demonstrated as a cost-effective treatment for decreasing the antisocial behavior of violent and chronic juvenile offenders. According to Henggeler (1997), MST cost

More detailed descriptions of some Blueprints programs are found in several OJJDP publications, which can be accessed online at OJJDP's Web site, ojjdp.ncjrs.org, or ordered through OJJDP's Juvenile Justice Clearinghouse by calling $800-638-8736$ :

- Functional Family Therapy (2000), NCJ 184743.

- The Incredible Years Training Series (2000), NCJ 173422.

- Mentoring-A Proven Delinquency Prevention Strategy (1997), NCJ 164834.

- Prenatal and Early Childhood Nurse Home Visitation (1998), NCJ 172875.

- Treating Serious Anti-Social Behavior in Youth: The MST Approach (1997), NCJ 165151.

Treatment Foster Care (1998), NCJ 173421.

approximately $\$ 3,500$ per youth in one replication site in South Carolina, which compared favorably with the average cost of the State's institutional placement at approximately $\$ 18,000$ per youth for a time period of about 59 weeks post referral. ${ }^{7}$

\section{Contact Information}

Keller Strother

MST Services, Inc.

268 West Coleman Boulevard, Suite 2-E

Mt. Pleasant, SC 29464

843-856-8226, ext. 14

843-856-8227 (fax)

ms@mstservices.com

www.mstservices.com

\section{Multidimensional Treatment Foster Care}

Incarceration of youth is costly and may have negative long-term effects on the youth involved. Alternatives to incarceration typically involve placement in a group care setting. However, as association with delinquent peers has been shown to be a strong predictor of future aggressive and delinquent behaviors, placing youth in group care with other juvenile delinquents may facilitate further bonding and social identification among group members.

A viable and cost-effective alternative to group care, Multidimensional Treatment Foster Care (MTFC) recruits, trains, and supervises foster families to provide participating youth with close supervision, fair and consistent limits and consequences, and a supportive relationship with an

7 Revised estimates reveal that the cost for MST treatment was $\$ 4,000$ plus an additional $\$ 4,000$ for use of other community services, which still compares favorably with a revised estimate of $\$ 20,000$ per youth in institutional placement (M.E. Swenson, MST Services, personal communication, March 27, 2001). adult. In MTFC, youth's contact with delinquent peers is minimized. The youth are supervised closely at home, in the community, and at school and are disciplined for rule violations and mentored by their MTFC parents. MTFC parent training emphasizes behavior management methods to provide youth with a structured and therapeutic living environment.

After they complete a preservice training, MTFC parents are matched with participating youth. A case manager, with the help of the MTFC parents, develops an individualized daily program for each youth that specifies the youth's schedule of activities and behavioral expectations and sets the number of points he or she can earn for satisfactory performance. The intervention is a gradual process based on youth's compliance with each level of program treatment. Three levels of supervision are defined in MTFC: level 1 requires adult supervision at all times, level 2 grants youth limited free time in the community, and level 3 allows for some peer activities that require less structure.

Routine consultation with and ongoing supervision of MTFC parents is a cornerstone of the program; parents are called daily to check on youth's progress and they also attend weekly group meetings. Family therapy is provided for the youth's biological (or adoptive) families, who are taught to use the structured system being used in the MTFC home to increase the likelihood of parenting success when the youth returns home.

One of the most significant problems in implementing an MTFC program is recruiting and training a group of competent MTFC parents. Another implementation problem is developing effective methods of communication for treatment staff 
and MTFC parents. The quality of teamwork is crucial to the success of MTFC cases.

Evaluations of MTFC youth show they had significantly fewer arrests during a 12-month followup than a control group of youth who participated in residential group care programs (an average of 2.6 offenses versus 5.4 offenses). During the first 2 years after treatment and program completion, youth who participated in the MTFC program spent significantly fewer days in lockup than youth who were placed in other community-based programs, resulting in a savings of $\$ 122,000$ for the program in incarceration costs. In addition, significantly fewer MTFC youth were ever incarcerated following treatment (Chamberlain, 1990). MTFC also has been shown to be effective for youth ages 9-18 leaving State mental hospital settings. Results showed that MTFC youth were placed out of the hospital at a significantly higher rate. During a 7-month followup, 33 percent of the control group remained in the hospital because no appropriate aftercare services could be found.

\section{Contact Information}

Patricia Chamberlain, Ph.D.

Oregon Social Learning Center

160 East Fourth Avenue

Eugene, OR 97401

541-485-2711

541-485-7087 (fax)

pattic@oslc.org

www.oslc.org

\section{Quantum Opportunities Program}

The Quantum Opportunities Program (QOP) was developed and implemented to benefit youth from families receiving public assistance. QOP provides participating youth with an intensive array of coordinated services and a sustained relationship with peers receiving similar services for the 4 years they are in high school.

QOP was designed to help youth overcome their disadvantaged backgrounds by compensating for their perceived and real lack of opportunities, providing them with a prosocial environment conducive to success, enhancing their skills levels to equip them for success, and reinforcing their achievements and positive actions. A QOP coordinator, who acts as surrogate parent, role model, advisor, and disciplinarian, provides services to a small group (no more than 25) of high-risk youth just

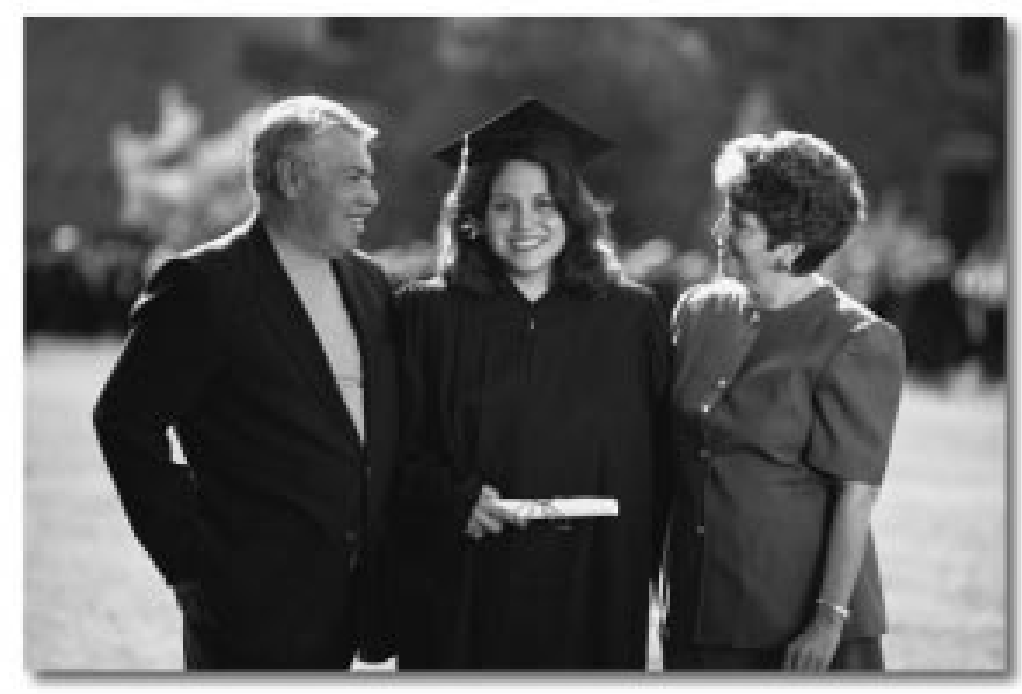

entering the ninth grade. The group environment helps youth bond with each other and with a caring adult, and this bonding appears to make the largest difference in student motivation and success. The program includes 250 hours per year of (1) educational opportunities (e.g., peer tutoring, computer-based instruction) to enhance basic academic skills, (2) development opportunities (e.g., family planning, career and college planning, cultural enrichment, personal development), and (3) community service opportunities (e.g., volunteering, working at public events). Financial incentives are offered to increase participation, completion, and long-range planning.

Results from the pilot test of this program, which was held from 1989 through 1993, indicated that QOP participants, when compared with a control group, were less likely to be arrested during the juvenile years (19 versus 23 percent), more likely to have graduated from high school (63 versus 42 percent), more likely to be enrolled in higher education or training ( 42 versus 16 percent), more likely to attend a 4 -year college (18 versus 5 percent), and less likely to become a teen parent (24 versus 38 percent). Six months after completing the program, 21 percent of QOP youth had taken part in a community project; 28 percent had volunteered as a tutor, counselor, or mentor; and 41 percent had volunteered at a nonprofit, charitable, school, or community group. In comparison, the percentages of control youth were 12,8 , and 11 , respectively.

\section{Contact Information}

C. Benjamin Lattimore

Opportunities Industrialization Centers of America, Inc.
1415 North Broad Street

Philadelphia, PA 19122

215-236-4500, ext. 251

215-236-7480 (fax)

oica@aol.com

www.oicworld.org

\section{Replication of Blueprints Programs}

The selection of a Blueprints program eliminates the need for an outcome evaluation in the short-term ( 4 or 5 years), because these programs have already been evaluated rigorously and continue to be evaluated, typically in clinical trials funded by the Federal Government. The critical issue for a Blueprints program is the quality of the implementation. To ensure quality implementation, training and technical assistance and monitoring of the implementation (a process evaluation) are essential.

OJJDP began supporting the Blueprints Initiative in April 1998 by providing 2-year training and technical assistance grants (3 years for Life Skills Training) through CSPV to interested sites. CSPV has contracted with the designers of the Blueprints programs to provide training and technical assistance and is conducting a process evaluation to ensure program fidelity at each site. Technical assistance includes help with choosing a Blueprints program, planning for program implementation, and carrying out the program, which includes training, onsite visits to troubleshoot problems, and regular telephone consultation. A total of 112 sites (including 290 schools) were selected to receive the assistance provided by these grants. Another 35 school/district sites currently are being assessed for selection. 
OJJDP supports four grant programs (Formula Grants, Title V Community Prevention Grants, Juvenile Accountability Incentive Block Grants, and Enforcing the Underage Drinking Laws) that award money to State governments. States then determine which programs they will support with the OJJDP funds. States and localities wishing to implement Blueprints programs may look to these four grant programs as sources for funding.

Typically, success depends on implementing the program as designed. Little is known, however, about the implementation problems that cause many programs to fail. In response, CSPV is accumulating data on the Blueprints replication sites regarding problems encountered, attempted solutions, efficacy of the solutions tried, and the reasons for their success or failure. To screen potential replication sites effectively, CSPV has also collected data on the organizational capacity, funding stability, commitment, and resources required for a high probability of success. CSPV is gathering this information through a process evaluation conducted at each site. The evaluation includes two onsite visits and one telephone interview per year with program implementers. Although it is too early to determine the extent of implementation integrity and all of the qualities relevant for success at each site, several themes have surfaced regarding the factors that may impede or enhance a successful program. A few notable issues are discussed below.

\section{Assessment and Planning}

Four general conditions are important in the earliest stages of planning and development to achieve successful implementation: needs assessment, strong buyin, adequate resources, and commitment. While this list is not exhaustive, these conditions can increase the probability of selecting and carrying out successful programs.

Needs assessment. Program initiators must begin by assessing the unique problems of the community or school setting in which the program will be implemented, clearly identifying the target population (e.g., age, gender, socioeconomic status, geographic area, level of risk), and choosing a program that will address the site's problems and target population. Failure to choose a program that matches the site's problems and population can lead to unsuccessful outcomes, even if the program is carried out with fidelity. For example, a drug prevention program meant for youth who have not yet initiated drug use may be ineffective if implemented in a treatment setting with substanceabusing youth.

Buy-in. Building a strong base of support early in the process among key decisionmakers and individuals responsible for program implementation is extremely important and requires time and effort. Achieving buy-in involves building consensus at the site around the program's philosophy and core components. Although it is preferable to have a team of staff with a strong leader, sites need to have at least one staff member who is given ample time to plan for successful implementation. This includes convening meetings with other staff and organizations to educate and garner support from all levels of the applying agency and to establish other pertinent interagency support. Most of the Blueprints sites had only one person who championed the program and worked on all planning and development issues. These sites could have benefited by organizing a team of individuals to manage the initial planning and development tasks, which are generally more than one person can handle. A team approach can improve communication among all levels of management and staff and can help build a strong base of support among many individuals within the organization so that, even if key individuals leave, others can carry the program forward. (In fact, sites should plan on turnover among key staff.) Failure to enlist from the start the active involvement and support of all key players, including implementing staff, can seriously jeopardize program success.

Adequate resources. A third important condition is obtaining all the required resources-tangible (e.g., monetary) and nontangible (e.g., staff support, client referral base)-for program planning and implementation. Sites should ensure that they have the appropriate funding for program assessment, planning, startup, and maintenance of all required program components. Failure to understand all of the resources necessary to implement a program (e.g., funding to cover costs of curriculums or supplemental materials, assessments, travel costs for training, and other expenses) and failure to commit to their acquisition can result in weak implementation and possible program failure.

Commitment. Related to buy-in, the last major condition is a commitment to highquality implementation. All programs have key elements that must be adhered to in order to ensure success. Program goals, principles, and core components must be identified during the planning stages and clearly communicated to all relevant persons involved in the implementation. Failure to understand and commit to the program's philosophical underpinnings and key components can undermine success.

\section{Implementation Challenges}

As of the publication of this Bulletin, CSPV's process evaluation remains under way. Therefore, formal data regarding the types of organizational, staff, financial, and other factors that contribute to implementation failure or success are not yet available. However, many themes regarding common challenges have emerged and offer a general picture of what communities will encounter when adopting a Blueprints program. One common theme is that problems are unavoidable. All sites, even those with the best planned implementations and most rigorous assessment processes, have confronted numerous hurdles. Another common theme is that, regardless of the unique qualities of each site and each Blueprints program, sites tended to face similar challenges. The most complex and timeconsuming challenges occurred during the startup phases (first 4-8 months) of program development. Most sites overcame initial hurdles only to run into a new set of challenges during later developmental stages.

Early challenges. Faced with hiring and training staff, accomplishing an array of administrative tasks, and raising funds, many practitioners reported feeling overwhelmed during the first 4 to 8 months of program development. Their frustrations included but were not necessarily limited to the following:

- Administrative tensions. Many staff faced difficulties tackling new work systems (e.g., paperwork, communication models, management styles) within preexisting, and sometimes conflicting, agency structures.

- Professional insecurities. Staff commonly felt that they did not have sufficient experience, training, or skills to implement new program models properly. Initial trainings were designed to introduce a new set of skills to staff, but many felt insecure about their new and developing talents. 
- Intra-agency and interagency links. The introduction of Blueprints programs into communities required agencies to hire new staff or assign existing staff to new workgroups. In many cases, agencies had to reach out to and build collaborative relationships with other institutions in the community. In most cases, developing relationships and lines of communication proved a complicated and sometimes frustrating task.

Support from onsite supervisors and administrators and regular contact with technical assistance providers (through training, telephone consultation, and onsite visits) and CSPV staff generally eased many of these early problems.

Later challenges. Process evaluation visits with sites that had implemented the program for at least 1 year revealed several common trends. After the first year, many of the early implementation challenges subsided as staff members' confidence increased and relationships within and among multiple agencies became more secure. However, implementation obstacles did not disappear entirely.

- Persistent challenges were the everpresent, low-level tensions (e.g., frustration with paperwork, the ongoing stress of providing time-intensive interventions) involved in providing services. While these challenges seemed daunting in the early stages of program development, site staff became used to paperwork demands and new work styles over time. Such tensions, although ongoing, rarely threatened program development.

- Episodic problems included short-term changes at a site (e.g., staff turnover, personality conflicts, administrative shifts within and between agencies). Such challenges required time and energy to manage but were often solved once new staff were hired, relationships within and between agencies were repaired, and staff members became accustomed to new working arrangements.

- Threatening problems occurred when sites experienced dramatic changes (e.g., loss of program champions, funding cuts, severed relationships with key agencies in the community) or confronted prominent individuals who opposed the philosophies behind and implementation of particular programs. Such problems posed serious challenges to program integrity.



During startup, such problems were more likely to result in site failure. Sites that had completed their first year of implementation often found that organizational and community investment in and motivation for their program helped them overcome such threatening problems.

\section{Implementation Strengths}

Sites had varying implementation strengths and weaknesses. Some had hired expert staff members whose commitment to the program and keen skills helped sites overcome problems with little disruption of implementation. Other sites had administrators whose unwavering support helped carry programs through myriad challenges. Although sites varied in their strengths and weaknesses, preliminary data suggest that four factors played a role in how programs overcame common problems: strong administrative support, presence of powerful program champions, staff expertise, and ongoing help from technical assistance providers. All of these factors not only determined whether and how sites overcame challenges-they also seemed to determine the overall quality of implementation.

Administrative support. Strong administrative support for programs was crucial. Administrators ensured that staff had the necessary resources to implement programs. In addition, they had the power to make organizational changes to accommodate new programs. As leaders, administrators also built staff support for programs and thus helped sites overcome problems with staff morale and motivation.

Program champions. These were the individuals who spearheaded implementation efforts. They helped maintain motivation, initiated necessary changes, and orchestrated completion of the many tasks necessary to make projects successful. In general, the most successful champions were those who commanded some power at the site. In some cases, champions were supervisors at a site and had good relations with both administrators and staff members. In other cases, champions were outsiders who had a long history of working well with site members.

Staff. A strong staff also contributed to program success. Staff members who supported or "bought in" to the philosophies of the programs, had the necessary experience and credentials, and were dedicated to learning new skills helped programs overcome a variety of obstacles. Staff members who were adequately reimbursed for their time were more effective implementers than those who were not.

Technical assistance providers. By recognizing the source of problems and suggesting solutions, technical assistance providers could help sites overcome weaknesses in many areas of implementation. During phone conferences and onsite meetings, technical assistance providers suggested ways to increase administrative support, identified appropriate program champions, 
and provided ongoing training to staff members. In a number of cases, technical assistance providers gave periodic presentations to schools, agencies, and community members to increase general awareness of and support for the Blueprints programs.

\section{Conclusion}

To date, much time and attention have been devoted to discovering which violence prevention programs are effective. By outlining high standards of program effectiveness, reviewing outcome evaluation results for numerous programs, and identifying successful programs, the Blueprints Initiative has helped answer some of the questions about what does and does not work in violence prevention. However, answering such questions is only the first step in meeting the greater challenge of preventing violence. To ensure continued program success, practitioners must turn their attention to quality of implementation. The preliminary data here suggest that obstacles are unavoidable. However, they do not have to lead to poor implementation or failure. Sites can overcome problems through a network of support at all levels-staff, supervisory, administrative, and community. These preliminary data also suggest that program designers have new roles in violence prevention. Once they have proved that their programs are effective, designers must address the new task of making their programs available to the public. At this stage, providing ongoing technical assistance to agencies and schools throughout the Nation requires as much coordination, care, and scientific rigor as were required in the research trial to prove that the programs are effective.

By supporting the replication of Blueprints programs, OJJDP has helped create a complete package of programs, technical assistance, and process evaluations (i.e., program monitoring) for States, communities, schools, and local agencies that are attempting to address the problems of violence, crime, and substance abuse. OJJDP's support of the Blueprints for Violence Prevention Initiative is not only a major effort to disseminate information on effective programs and provide funding for training and technical assistance to help these programs get established in communities, it is also an attempt to systematically gather information on the challenges that arise in adopting new programs and in widely disseminating them.

\section{For Further Information}

To receive information on the Blueprints for Violence Prevention Initiative or to order any of the Blueprints publications, contact:

Center for the Study and Prevention of Violence

University of Colorado at Boulder

Institute of Behavioral Science, \#10

Campus Box 439

Boulder, CO 80309-0439

303-492-8465

303-443-3297 (fax)

blueprints@colorado.edu

www.colorado.edu/cspv/blueprints

Office of Juvenile Justice and Delinquency Prevention

Training and Technical Assistance

Division

810 Seventh Street NW.

Washington, DC 20531

202-307-5940

202-353-9095 (fax)

ojjdp.ncjrs.org

\section{References}

American Psychiatric Association. 1994.

Diagnostic and Statistical Manual of Mental Disorders, 4th ed. Washington, DC:

American Psychiatric Association.

Aos, S., Phipps, P., Baroski, R., and Lieb, R. 1999. The Comparative Costs and Benefits of Programs To Reduce Crime: A Review of National Research With Implications for Washington State. Olympia, WA: Washington State Institute for Public Policy.

Campbell, S.B. 1990. Behavior Problems in Preschool Children: Clinical and Developmental Issues. New York, NY: Guilford Press.

Chamberlain, P. 1990. Comparative evaluation of specialized foster care for seriously delinquent youths: A first step. Community Alternatives: International Journal of Family Care 2:21-36.

Coie, J.D. 1990. Toward a theory of peer rejection. In Peer Rejection in Childhood (Cambridge Studies in Social and Emotional Development), edited by S.R. Asher and J.D. Coie. New York, NY: Cambridge University Press, pp. 365-398.

Glass, G.V. 1976. Primary, secondary and meta-analysis. Educational Researcher 5(10):3-8.

Greenwood, P.W., Model, K.E., Rydell, C.P., and Chiesa, J. 1996. Diverting Children From a Life of Crime: Measuring Costs and Benefits. Santa Monica, CA: The RAND Corporation.

Grossman, J.B., and Garry, E.M. 1997. Mentoring-A Proven Delinquency Prevention Strategy. Bulletin. Washington, DC: U.S. Department of Justice, Office of Justice Programs, Office of Juvenile Justice and Delinquency Prevention.

Henggeler, S.W. 1997. Treating Serious AntiSocial Behavior in Youth: The MST Approach. Bulletin. Washington, DC: U.S. Department of Justice, Office of Justice Programs, Office of Juvenile Justice and Delinquency Prevention.

Karoly, L.A., Everingham, S.S., Hoube, J., Kilburn, R., Rydell, C.P., Sanders, M., and Greenwood, P.W. 1998. Investing in Our Children: What We Know and Don't Know About the Costs and Benefits of Early Childhood Interventions. MR-898. Santa Monica, CA: The RAND Corporation.

Lipsey, M.W. 1992. Juvenile delinquency treatment: A meta-analytic inquiry into the variability of effects. In Meta Analysis for Explanation: A Casebook, edited by T.D. Cook, H. Cooper, D.S. Corday, H. Hartmann, L.V. Hedges, R.J. Light, T.A. Louis, and F. Mosteller. New York, NY: Russell Sage Foundation, pp. 83-127.

Lipsey, M.W. 1999. Can intervention rehabilitate serious delinquents? Annals of the American Academy of Political and Social Science 564:142-166.

Melton, G.B., Limber, S.P., Cunningham, P., Osgood, D.W., Chambers, J., Flerx, V., Henggeler, S., and Nation, M. 1998. Violence Among Rural Youth. Final Report. Washington, DC: U.S. Department of Justice, Office of Justice Programs, Office of Juvenile Justice and Delinquency Prevention.

Olds, D., Henderson, C.R., Cole, R., Eckenrode, J., Kitzman, H., Luckey, D., Pettitt, L., Sidora, K., Morris, P., and Powers, J. 1998. Long-term effects of nurse home visitation on children's criminal and antisocial 
behavior: 15-year follow-up of a randomized trial. Journal of the American Medical Association 280(14):1238-1244.

Olds, D., Henderson, C., Phelps, C., Kitzman, H., and Hanks, C. 1993. Effect of prenatal and infancy nurse home visitation on government spending. Medical Care 31(2):155-174.

Olds, D.L., Eckenrode, J., Henderson, C.R., Jr., Kitzman, H., Powers, J., Cole, R., Sidora, K., Morris, P., Pettitt, L., and Luckey, D. 1997. Long-term effects of home visitation on maternal life course and child abuse and neglect: 15-year follow-up of a randomized trial. Journal of the American Medical Association 278(8):637-643.

Olds, D.L., Henderson, C.R., Chamberlain, R., and Tatelbaum, R. 1986. Preventing child abuse and neglect: A randomized trial of nurse home visitation. Pediatrics 78(1):65-78.

Olds, D.L., Henderson, C.R., and Tatelbaum, R. 1994a. Intellectual impairment in children of women who smoke cigarettes during pregnancy. Pediatrics 93(2):221-227.

Olds, D.L., Henderson, C.R., and Tatelbaum, R. 1994b. Prevention of intellectual impairment in children of women who smoke cigarettes during pregnancy. Pediatrics 93(2):228-233.

Olweus, D. 1993a. Bullying at School: What We Know and What We Can Do. Cambridge, United Kingdom: Blackwell.

Olweus, D. 1993b. Victimization by peers: Antecedents and long-term outcomes. In Social Withdrawal, Inhibition, and Shyness, edited by K.H. Rubin and J.B. Asendorf. Hillsdale, NJ: Erlbaum, pp. 315-341.

Webster-Stratton, C. 1990. Long-term followup of families with young conduct-problem children: From preschool to grade school. Journal of Clinical Child Psychology 19:144-149.
Webster-Stratton, C., and Hammond, M. 1997. Treating children with early-onset conduct problems: A comparison of child and parent training interventions. Journal of Consulting and Clinical Psychology 65(1):93-109.

Webster-Stratton, C., Reid, J., and Hammond, M. 2000. Preventing conduct problems, promoting social competence: A parent and teacher training partnership for a multi-ethnic, Head Start population. Unpublished. Seattle, WA: University of Washington, School of Nursing, Department of Family and Child Nursing, Parenting Clinic.
This Bulletin was prepared under grant number 98-MU-MU-K005 from the Office of Juvenile Justice and Delinquency Prevention, U.S. Department of Justice.

Points of view or opinions expressed in this document are those of the authors and do not necessarily represent the official position or policies of OJJDP or the U.S. Department of Justice.

The Office of Juvenile Justice and Delinquency Prevention is a component of the Office of Justice Programs, which also includes the Bureau of Justice Assistance, the Bureau of Justice Statistics, the National Institute of Justice, and the Office for Victims of Crime.

\title{
Acknowledgments
}

Delbert Elliott, Ph.D., is Director of the Center for the Study and Prevention of Violence (CSPV), University of Colorado at Boulder. Sharon Mihalic, M.A., Director, Katherine Irwin, Evaluation Manager, Abigail Fagan, Life Skills Training Manager, and Diane Hansen, Training and Technical Assistance Manager, work on CSPV's Blueprints for Violence Prevention Initiative.

Photograph page 5 copyright (C) 1997 PhotoDisc, Inc.; photographs pages 7 and 13 copyright (C) 2001 PhotoDisc, Inc.; photograph page 8 copyright (C) 2001 Corbis; photograph page 11 copyright (C) 1999 PhotoDisc, Inc.

\section{Share With Your Colleagues}

Unless otherwise noted, OJJDP publications are not copyright protected. We encourage you to reproduce this document, share it with your colleagues, and reprint it in your newsletter or journal. However, if you reprint, please cite OJJDP and the authors of this Bulletin. We are also interested in your feedback, such as how you received a copy, how you intend to use the information, and how OJJDP materials meet your individual or agency needs. Please direct your comments and questions to:

\author{
Juvenile Justice Clearinghouse \\ Publication Reprint/Feedback \\ P.O. Box 6000 \\ Rockville, MD 20849-6000 \\ 800-638-8736 \\ 301-519-5600 (fax) \\ E-mail: tellncjrs@ncjrs.org
}




\section{U.S. Department of Justice}

Office of Justice Programs

Office of Juvenile Justice and Delinquency Prevention
PRESORTED STANDARD POSTAGE \& FEES PAID DOJ/OJJDP PERMIT NO. G-91

Washington, DC 20531

Official Business

Penalty for Private Use $\$ 300$ 